Original article

\title{
AUTOLOGOUS VENOUS GRAFTING PROMOTES HEALING AND REDUCES ADHESION FORMATION IN EXPERIMENTALLY SEVERED CANINE SUPERFICIAL DIGITAL FLEXOR TENDONS
}

\author{
M. H. DARADKA, M. A. MALKAWI, Z. B. ISMAIL \\ \& M. A. ALSHEHABAT \\ Department of Veterinary Clinical Sciences, Faculty of Veterinary Medicine, \\ Jordan University of Science and Technology, Irbid, Jordan
}

\section{Summary}

Daradka, M. H., M. A. Malkawi, Z. B. Ismail \& M. A. Alshehabat, 2016. Autologous venous grafting promotes healing and reduces adhesion formation in experimentally severed canine superficial digital flexor tendons. Bulg. J. Vet. Med., 19, No 3, 233-241.

\begin{abstract}
The objectives of this study were to evaluate healing of experimentally severed superficial digital flexor tendons of the canine hind limb repaired by apposition using a Kessler pattern with no augmentation, or augmentation with an everted autologous venous graft or non-everted autologous venous graft. A total of 30 healthy, orthopaedically and neurologically sound mongrel dogs were used in this study. Dogs were randomly allocated into one of the three groups: control group $\left(\mathrm{G}_{\mathrm{C}}\right)$ : the severed tendon was repaired with Kessler technique only and no grafting, $\mathrm{G}_{\mathrm{NEv}}$ : the severed tendon was repaired using Kessler technique and "non-everted venous graft" and $\mathrm{G}_{\mathrm{Ev}}$ : the severed tendon was repaired with Kessler technique and "an everted venous graft". Post-operatively, at day 42, the site of surgery was evaluated grossly and histologically. In the control group, $30 \%$ of dogs showed no healing of the severed tendon. Both types of venous grafts ("everted" and "non-everted") resulted in improved fibroblastic proliferation at the site of injury. The amount of adhesion appeared significantly less in grafted sites compared to non-grafted tendons. When compared between the 2 types of venous grafts, the adhesion formation appeared to be less pronounced in $G_{\mathrm{Ev}}$ group than that in $\mathrm{G}_{\mathrm{NEv}}$ group. Autologous venous grafts appear to significantly improve fibroblastic proliferation and reduce adhesion tissue formation particularly when utilising "everted autologous venous graft". These results might suggest a beneficial effect when utilising venous grafts along with the traditional treatment procedure of severed digital flexor tendons in dogs.
\end{abstract}

Key words: tendon injury, dogs, venous graft, healing, adhesion formation

\section{INTRODUCTION}

Tendons are a specialised form of fibrous connective tissues responsible for transmitting mechanical forces from skeletal muscle to bone, stabilising joints and act- ing as a shock absorber with a unique ability to glide through the surrounding tissues (Vaughan, 1985; Saini et al., 2002). Disorders of flexor tendons are commonly 
caused by direct sharp trauma resulting in partial or complete severance. Clinical signs depend on the number of tendons involved and include postural and gait abnormalities (Vaughan, 1985). The current recommendation of managing severed tendons is surgical tennorhaphy, whose main goals are to restore tendon gliding function, minimise gap formation between the tendon ends, reduce adhesion formation, and preserve vascularisation to the tendon (Vaughan, 1985). Despite advances in the surgical techniques and postoperative management, difficulties with tendon repair (delayed return of tendon strength for approximately 3 weeks following repair, gap formation, longitudinal fibre orientation complicating sutureholding, adhesion formation) are faced. Furthermore, tendon repair encounters technical (essentially physical problems) and biological (concerns primarily with vascularisation and peri-tendinous fibrosis causing adhesion formation) issues (Akali et al., 1999; Jaibaji, 2000; Ferguson \& Rinker, 2006; Temizet al., 2008; Mousavi et al., 2009).

There has been considerable research conducted in the past in an effort to better understand the biological response of tendon injury and to improve the outcome of surgical technique performed (Amadioet al., 1988; Lilly \& Messer, 2006; Bhavsar $\&$ Shettko, 2010). A plethora of techniques and materials have been utilised to overcome such complications using synthetic or natural products (Lilly \& Messer, 2006; Bhavsar \& Shettko, 2010). In dogs, an autologous venous graft obtained from the external jugular vein showed substantially reduced adhesion formation (Bins Ely et al., 1999). In human patients presented with acute or chronic tendon injury, an autologous graft obtained from the saphenous vein reduced adhesion for- mation and improved digit function (Lilly \& Messer, 2006).

The objectives of this study were to evaluate healing of experimentally severed superficial digital flexor tendons of the canine hind limb repaired by apposition using a Kessler pattern with no augmentation, or augmentation with an everted autologous venous graft or noneverted autologous venous graft.

\section{MATERIALS AND METHODS}

This study was approved by the Institutional Animal Care and Use Committee of Jordan University of Science and Technology.

A total of 30 mongrel dogs (21 female and 9 male) with mean age of 19.4 months and mean weight of $13.6 \mathrm{~kg}$ were selected for this study. Complete orthopaedic and neurological examination was performed. The general health status of all dogs was evaluated by performing complete blood count, biochemistry panel and urinalysis. Dogs were included in the study only if they were clinically healthy, had no history or clinical signs suggestive of orthopaedic or neurological diseases.

The dogs were randomly allocated into one of the three groups $(n=10): G_{C}, G_{N E v}$ and $G_{E v}$ based on the type of treatment each group received. In all groups the superficial flexor tendon of the third digit was completely severed. In $\mathrm{G}_{\mathrm{C}}$ group, the tendon was repaired with Kessler technique only (no grafting). In $\mathrm{G}_{\mathrm{NEv}}$ group, the tendon was repaired with Kessler technique and received a "non-everted venous graft". In $\mathrm{G}_{\mathrm{Ev}}$ group, the tendon was repaired with Kessler technique and received an "everted venous graft".

For surgery, dogs were premedicated using an intramuscular injection of 0.5 $\mathrm{mg} / \mathrm{kg}$ xylazine hydrochloride (Xyla-jet, 


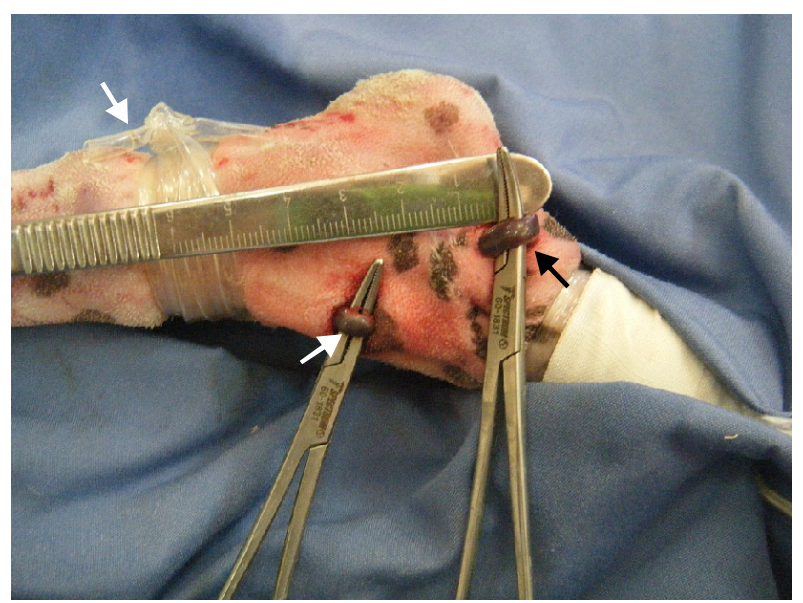

Fig. 1. Harvesting of the venous autograft using the lateral saphenous vein.

Phoenix Pharmaceuticals Inc, St Joseph, MO, USA) and $0.04 \mathrm{mg} / \mathrm{kg}$ atropine sulfate (Bimedia-Mtc Animal Health Inc., Vetoquinol Canada Inc., Canada). Anaesthesia was then induced and maintained using intravenous injections of ketamine hydrochloride $(15 \mathrm{mg} / \mathrm{kg}$, Fort Dodge Animal Health, Fort Dodge, IO, USA). The surgical procedure was performed under aseptic conditions using the right hind limb. To obtain the venous grafts, a mid-tibia tourniquet was applied. Two approximately $5 \mathrm{~cm}$ long incisions - proximal and distal were made over the lateral saphenous vein (Fig. 1). The vein was then isolated, double-ligated and bluntly dissected out and extra connective tissues were removed. The harvested venous segment (approximately $4 \mathrm{~cm}$ long) was then transferred into a normal saline solution containing 10\% gentamicin (GentaVet, Butler Schein Animal Health, USA). The donor site was then routinely closed.

The recipient site was aseptically prepared. The superficial digital flexor tendon of the third digit was isolated on the plantar aspect of the area corresponding to mid-metatarsal region of the right hind limb by making a $3 \mathrm{~cm}$ skin incision and the tendon was vertically severed using a scalpel blade (Fig. 2). In the control group, the tendon was severed and only sutured using Kessler technique, without grafting, using 4-0 size Nylon. In $\mathrm{G}_{\mathrm{NEv}}$ group, the harvested venous segment was cut longitudinally and gently inserted through the cut ends of the tendon with the vein intima layer facing the paratenon layer of the tendon, then the tendon was sutured and the inserted graft was then gently pulled back over the sutured tendon (Fig. 3). In animals from the $\mathrm{G}_{\mathrm{Ev}}$ group, the harvested venous segment was everted and then inserted through the cut ends of the tendon with the vein adventitia facing the parate-

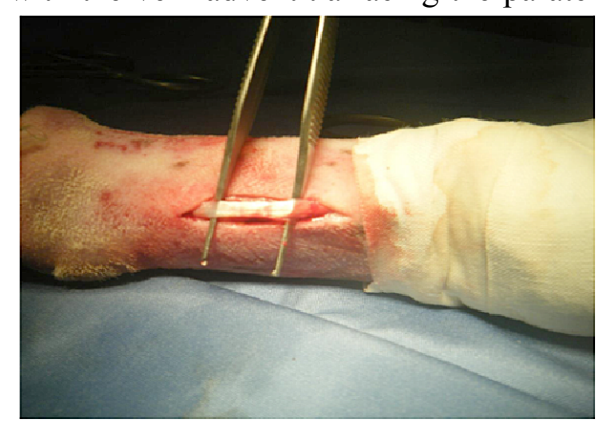

Fig. 2. The superficial digital flexor tendon of the third digit was vertically severed prior to surgical repair. 
non layer of the tendon (Fig. 4). In both $\mathrm{G}_{\mathrm{NEv}}$ and $\mathrm{G}_{\mathrm{Ev}}$ groups, the free edges, proximally and distally, of the grafted vein were sutured to the tendon using 4-0 Monocryl suture. The surgical site was then closed routinely and the surgical site was covered with a non-adhesive dressing (Tegaderm $^{\mathrm{TM}}, 3 \mathrm{M}^{\mathrm{TM}}$, USA).

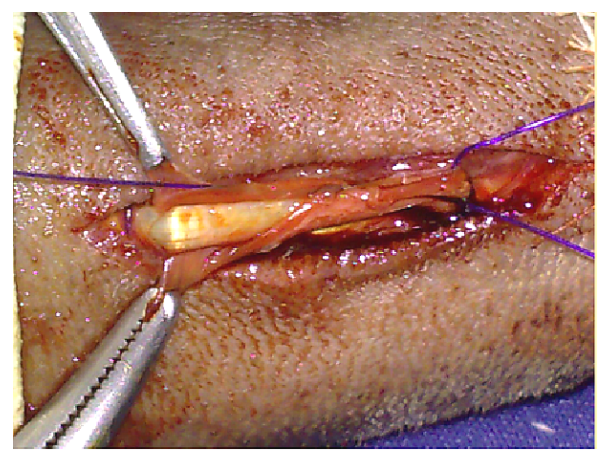

Fig. 3. The severed tendon was repaired using traditional Kessler technique augmented using non-everted autologous saphenous venous graft.

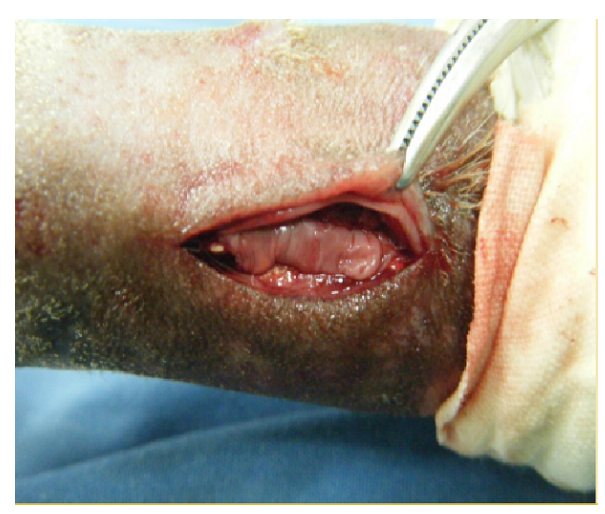

Fig. 4. The severed tendon was repaired using traditional Kessler technique augmented using everted autologous saphenous venous graft.

All dogs were the allowed to recover from anaesthesia. Post-operative pain was controlled by subcutaneous injection of $1 \mathrm{mg} / \mathrm{kg}$ flunixin meglumine, once a day for three days (Schering-Plough, France).
All dogs received amoxicillin/clavulanic acid (13.75 mg/kg p.o. BID) for 5 days as a perioperative antibiotic therapy. Exercise was restricted only to cage movement, urination and defecation purposes. The surgical site was monitored for the cardinal signs of inflammation on a daily basis for a week and sutures were removed 2 weeks post operatively.

Dogs were humanely euthanised on day 42 after surgery using an intravenous aneasthetic overdose $(80 \mathrm{mg} / \mathrm{kg}$ thiopental sodium, Abbott Laboratories, Chicago, IL, U.S.A.). The surgery site was dissected, photographed and evaluated for adhesion formation. The degree of adhesion formation was scored according to a criteria established according the authors' personal clinical skills as described in Table 1. Tissue specimens were collected from the surgery site and fixed in $10 \%$ buffered formalin. Specimens were then processed routinely for histological evaluation. Cross and longitudinal sections of 0.5 micrometer thickness were made and stained with haematoxylin and eosin stain (H\&E, Poly Scientific, Bay Shore, NY, USA). Criteria used in the histological evaluation were: presence and severity of inflammation, signs of tendon healing and formation of adhesion tissues between the severed tendon and the surrounding tissues.

\section{Statistical analysis}

Statistical differences in the adhesion scores were assessed using Wilcoxon ranked sign test. Median, $25^{\text {th }}$ and $75^{\text {th }}$ percentiles for adhesion scores were calculated. Differences were considered statistically significant at $\mathrm{P}$ value less than 0.05 . The data was analysed using statistical software SPSS (version 19, SPSS Inc, Chicago, IL, USA). 
Table 1. Criteria and the grades used to evaluate the degree of adhesion formation at the graft site in dogs with experimentally severed flexor tendons

\begin{tabular}{ll}
\hline Grade & \multicolumn{1}{c}{ Criteria } \\
\hline 0 & $\begin{array}{l}\text { Normal. On skin and subcutaneous dissection, the tendon is seen freely moving } \\
\text { without any resistance. }\end{array}$ \\
\hline 1 & $\begin{array}{l}\text { Substantial connective and fibrous tissue is found around the tendon sheath, but } \\
\text { the tendon is still freely movable and has a normal function. }\end{array}$ \\
\hline 2 & $\begin{array}{l}\text { Mild reactive connective tissue and the tendon is hypertrophic. Limited movement } \\
\text { of the tendon within the surrounding tissues upon passive movement of the joint. }\end{array}$ \\
\hline 4 & $\begin{array}{l}\text { Large quantity of connective tissue. The tendon adheres to surrounding tissues. } \\
\text { Limited movement. No passive movement of the joint. }\end{array}$ \\
\hline
\end{tabular}

Table 2. Adhesions scores of dogs from the different groups: $G_{C}$ the tendon was repaired with Kessler technique only (no grafting); $\mathrm{G}_{\mathrm{NEv}}$ : the tendon was repaired using Kessler technique and "non-everted venous graft" and $\mathrm{G}_{\mathrm{Ev}}$ : the tendon was repaired with Kessler technique and "an everted venous graft"

\begin{tabular}{lcccc}
\hline & Number & $25^{\text {th }}$ percentile & $50^{\text {th }}$ (median) percentile & $75^{\text {th }}$ percentile \\
\hline Group $\mathrm{G}_{\mathrm{C}}$ & 10 & 2.00 & $2.50^{\mathrm{A}}$ & 3.00 \\
Group $\mathrm{G}_{\mathrm{NEv}}$ & 10 & 1.00 & $1.00^{\mathrm{B}}$ & 1.25 \\
Group $\mathrm{G}_{\mathrm{Ev}}$ & 10 & 1.00 & $1.00^{\mathrm{B}}$ & 2.00 \\
\hline
\end{tabular}

${ }^{\mathrm{A}-\mathrm{B}}$ Values are significant at $\mathrm{P}<0.05$.

\section{RESULTS}

All animals completed the study without any complications. The statistical analysis of the adhesion score revealed that $G_{C}$ group was significantly different from $\mathrm{G}_{\mathrm{NEv}}$ and $\mathrm{G}_{\mathrm{Ev}}$ groups while no statistical differences were observed between $\mathrm{G}_{\mathrm{NEv}}$ and $\mathrm{G}_{\mathrm{Ev}}$ groups (Table 2). In the $\mathrm{G}_{\mathrm{C}}$ group, $50 \%$ of dogs had a grade 2 adhesion scores, $50 \%$ of dogs had grade 3 adhesion scores and $30 \%$ of dogs showed no healing of the severed tendon (Fig. 5). In the $\mathrm{G}_{\mathrm{NEv}}$ group, $80 \%$ of dogs had grade 1 adhesion score, while $20 \%$ of dogs had a grade 2 adhesion scores (Fig. 6). In $\mathrm{G}_{\mathrm{Ev}}$ group, $60 \%$ of dogs had a grade 1 adhesion score, $40 \%$ of dogs had a grade 2 adhesion score (Fig. 6).

In the histological evaluation, there was few collagen and fibroblasts and extensive formation of adhesion in the $G_{C}$ group (Fig. 7A). In this group, 70\% of dogs had union between the tendon stumps. The surgical site was marked by fibroblastic activity and immature collagen fibres. The collagen fibres appeared to be longitudinally arranged with few blood vessels. In the $\mathrm{G}_{\mathrm{NE}}$ group, fibroblast proliferation was prominent; there was more neovascularisation, less adhesion tissue formation and more union when 

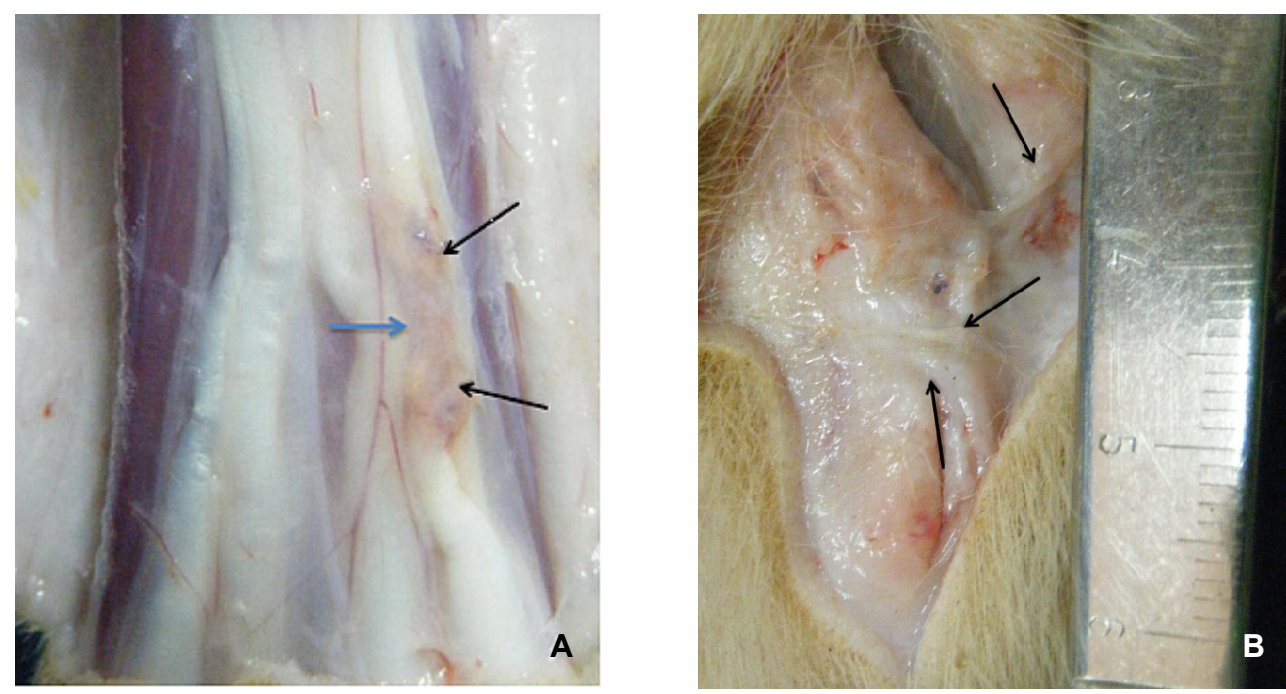

Fig. 5. Non healing of severed superficial flexor tendon (A) and adhesion score grade 3 (B) after repair using un augmented Kessler technique.
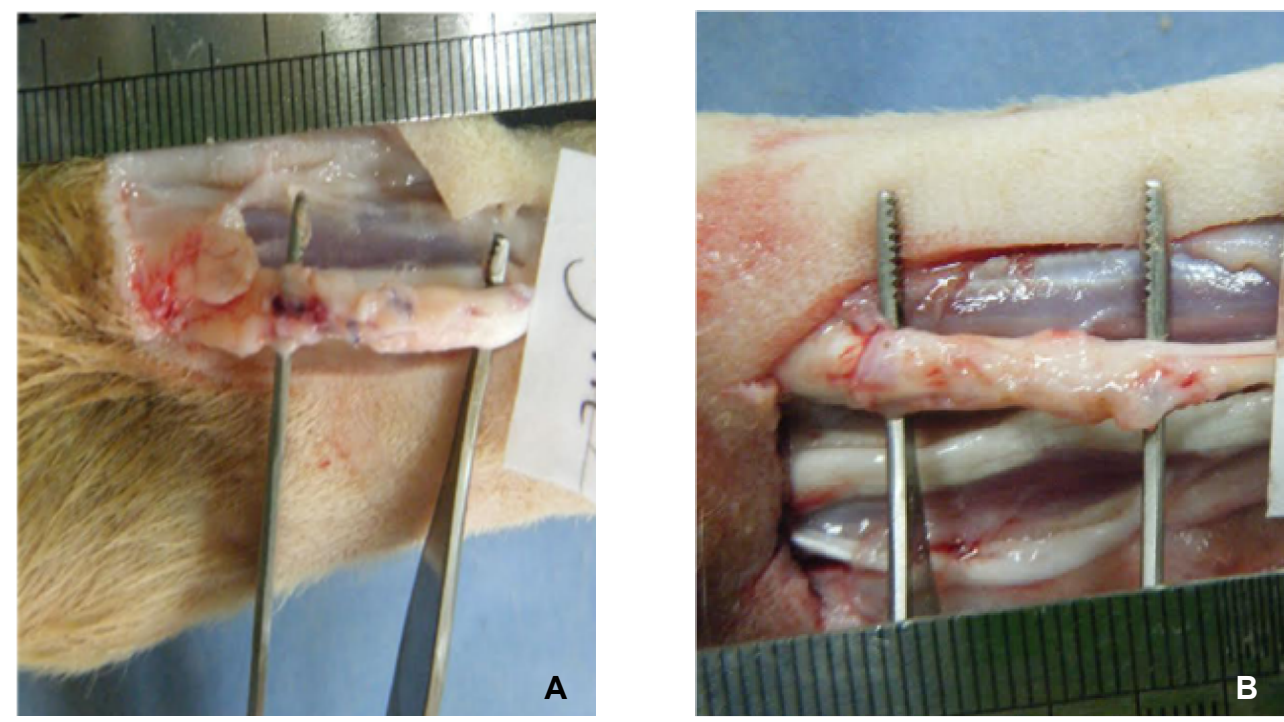

Fig. 6. Adhesion score grade 1 (A) and grade 2 (B) in severed superficial flexor tendons repaired using non-everted and everted saphenous venous autografts respectively.

compared with $\mathrm{G}_{\mathrm{C}}$ group. The tissue at the tendon stumps was more homogenous with less inflammatory reactions and equal amount of fibroblast and collagen fibres that appeared to be longitudinally arranged. In the $\mathrm{G}_{\mathrm{Ev}}$ group (Fig. 7B), there was more fibroblast proliferation and neovascularisation, while less adhesion formation when compared with $\mathrm{G}_{\mathrm{NEv}}$ group (Fig. 7C). 

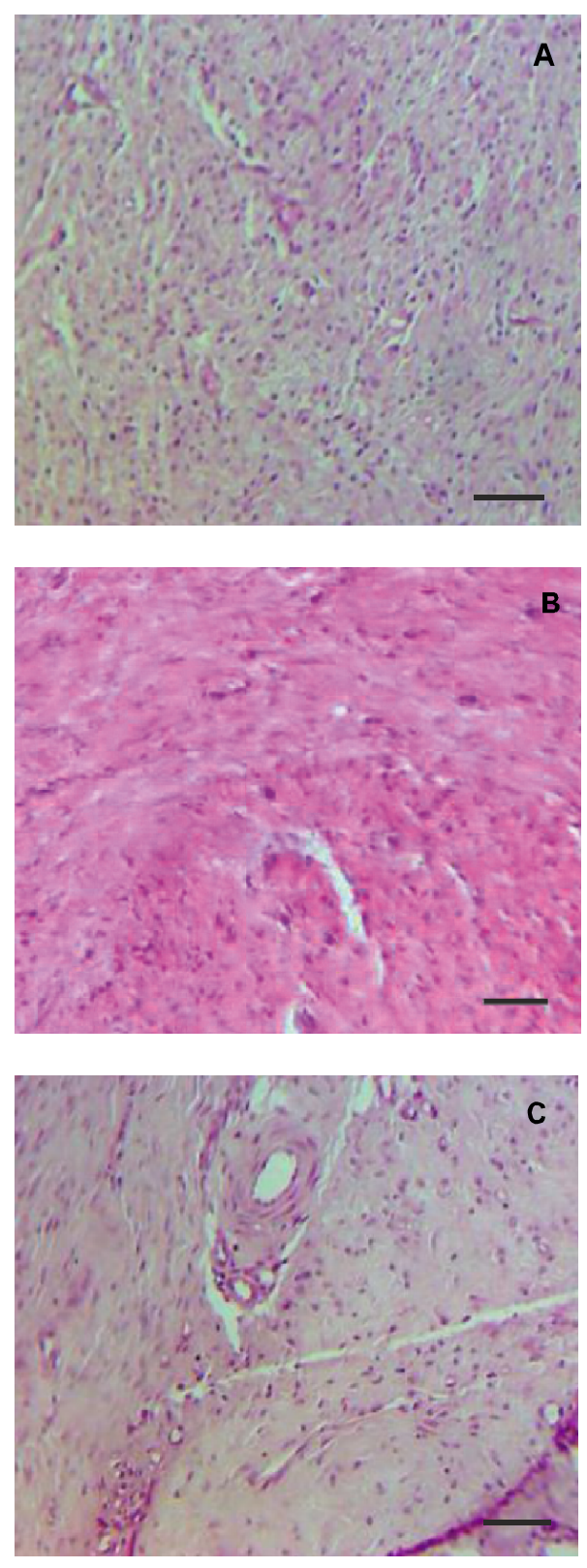

Fig. 7. A. Tendon repair using Kessler technique only; B. The tendon was repaired using Kessler technique and received a non-everted venous graft; C. Tendon repair using Kessler technique and received an everted venous graft $(\mathrm{H} \& \mathrm{E}, \mathrm{bar}=200 \mu \mathrm{m})$.

\section{DISCUSSION}

In this study, the gross and histological evaluation of repaired tendon healing using traditional surgical techniques augmented by an either everted or noneverted saphenous venous graft suggested a clinically favourable outcome when compared to healing of non-grafted tendons. The healing of grafted tendons was more complete with substantially less adhesion formation that usually occurs with traditionally performed surgical techniques such as Kessler surgical procedure. It was proposed that autologous venous grafts may act as a protective shield to help reduce adhesion formation with the surrounding tissue and thus maintaining the gliding function of the tendon (Biro $\&$ Vamhidy, 1985). In addition, it may act as a source of cellular elements that enhances healing. Although there were no significant differences in regard of adhesion scores between $\mathrm{G}_{\mathrm{NEv}}$ and $\mathrm{G}_{\mathrm{Ev}}$ groups, the histological evaluation revealed substantially less formation of adhesion tissues in $\mathrm{G}_{\mathrm{Ev}}$ group. Adhesion formation after tendon repair is one of the major clinical concerns because it may contribute to poor functional outcome (Lilly \& Messer, 2006).

In this study, the groups that received the venous grafts had a higher extent of vascularisation, more collagen and fibroblastic reactions. These findings are in agreement with previous work reported in dogs, rabbits, donkeys and human model (Biro \& Vamhidy, 1985; Moosavi et al., 2005). The findings presented in here may suggest that both techniques are clinically acceptable to manage severed digital tendons in dogs. However, everted graft was associated with better outcome based on relatively lower adhesion formation, more collagen and fibroblastic reactions. It has been suggested that diffusion is more im- 
portant than perfusion to nourish tendons. Utilisation of autologous venous graft to act as a protective shield may have improved the tendon nourishment by creating better environment for the diffusion process.

Generally, the ideal graft must be easy to collect, apply, biocompatible, not interfering with tendon movement, not adding undue bulk, and integrate at the site of repair long enough to allow tendon healing. In this study, it was not technically difficult to harvest or apply the graft to the severed tendon. Moreover, the grafted vein integrated into the recipient site and did not seem to add any undue bulk.

Although the diagnosis of tendon problems including cuts and lacerations in dogs is easily accomplished, the clinical management is a rather more difficult task because of prolonged healing process and potential inevitable adhesion formation with the surrounding tissues which may compromise the limb function. In this study, it was proven that the use of either everted or non-everted saphenous venous graft results in more clinically favourable outcome. Based on these results we recommend the use of an everted autologous venous graft to augment the tendon repair using the traditional Kessler techniques in severed digital flexor tendons in dogs.

\section{ACKNOWLEDGEMENTS}

The authors would like to thank the Deanship of Research at Jordan University of Science and Technology for sponsoring this project.

\section{REFERENCES}

Akali, A., U. Khan, P. T. Khaw \& A. D. McGrouther, 1999. Decrease in adhesion formation by a single application of 5-fluorouracil after flexor tendon injury. Plastic Reconstructive Surgery, 103, 151-158.
Amadio, P. C., M. B. Wood, W. P. Cooney \& S. D. Bogard, 1988. Staged flexor tendon reconstruction in the fingers and hand. Journal of Hand Surgery, 13, 559-562.

Bhavsar, D., D. Shettko \& M. Tenenhaus, 2010. Encircling the tendon repair site with collagen-GAG reduces the formation of postoperative tendon adhesions in a chicken flexor tendon model. Journal of Surgery Research, 159, 765-771.

Bins Ely, J., D. Fagundes, P. O. Gomes, O. J. Pereira Filho \& S. Goldenberg, 1999. Tenorrhaphy and tendinous venous envelope (TVE). A morphofunctional study in 24 beagles dogs. Chirurgie de la Main, 18, 226-235.

Biro, V. \& L. Vámhidy, 1985. Experimental tendon sheath reconstruction using autologous vein transplants. Handchirurgie, Mikrochirurgie, Plastische Chirurgie, 17, 1417.

Ferguson, R. E. \& B. Rinker, 2006. The use of a hydrogel sealant on flexor tendon repairs to prevent adhesion formation. Annals of Plastic Surgery, 56, 54-58.

Jaibaji, M., 2000. Advances in the biology of zone II flexor tendon healing and adhesion formation. Annals of Plastic Surgery, 45, 83-92.

Lilly, S. I. \& T. M. Messer, 2006. Complications after treatment of flexor tendon injuries. Journal of American Academy of Orthopedic Surgery, 14, 387-396.

Moosavi, S. R., A. R. K. Motamedi \& A. M. Tofigh, 2005. Use of vein graft as a tendon sheath substitute following tendon repair: An innovative technique in tendon surgery. International Journal of Surgery, $\mathbf{3}$, 113-116.

Mousavi, S. R., Z. Mehdikhah \& N. Tadayon, 2009. Flexor tendon repair in children with zone 2 injuries: An innovative technique using autogenous vein. Journal of Pediatric Surgery, 44, 1662-1665.

Saini, N. S., K. S. Roy, P. S. Bansal, B. Singh \& P. S. Simran, 2002. A preliminary study on the effect of ultrasound therapy on the healing of surgically severed achilles ten- 
dons in five dogs. Journal of Veterinary Medicine A, 49, 321-328.

Temiz, A., C. Ozturk, A. Bakunov, K. Kara \& T. Kaleli, 2008. A new material for prevention of peritendinous fibrotic adhesions after tendon repair: Oxidised regenerated cellulose an absorbable adhesion barrier. International Orthopaedics, 32, 389-394.

Vaughan, L. C., 1985. The management of tendon injuries in dogs. Journal of Small Animal Practice, 26, 133-142.

Paper received 03.12.2015; accepted for publication 22.01.2016

\section{Correspondence:}

Dr. M. A. Daradka

Department of Veterinary Clinical Sciences, Faculty of Veterinary Medicine

Jordan University of Science and Technology PO Box 3030, Irbid 22110, Jordan

e-mail: daradkah@just.edu.jo 